\title{
Monitoring of priorii information at complex product failure of single use in the process of its creation
}

\author{
Yuri Tsarev ${ }^{1, *}$ \\ ${ }^{1}$ Don State Technical University, 1, Gagarin sq., Rostov-on-Don, 344000, Russia
}

\begin{abstract}
A variant of the parametric representation of a single use complex product in the process of its creation during testing is described, when structural failures of the product or its component parts according to one or more parameters specified in the technical specification, requires the implementation of modifications is required, leading to changes in general set and repetition trials, however, it is possible to reduce the volume of tests by taking into account a priorii information. This is especially true, while ensuring the reliability of complex space products of single use, the components of which pass the first stages of ground tests, and then as part of complex space products - the stages of flight tests. The structural failure of any component of a space product during ground testing must not have the effect of occurring during flight tests as if it had been part of the product. Meanwhile, the completion of the component element of a singleuse product, the structural failure of which occurred at the stage of flight tests in the product, and the evaluation of its effectiveness, can be carried out at the stage of ground tests, in the case of a complex product consideration in parametric form. It can significantly reduce the cost of flight testing of a complex product, in the case of the product composite element effective refinement at the stage of ground testing, without a significant (temporary) reduction in the overall reliability of a single use complex product.
\end{abstract}

\section{Introduction}

There is always a problem of minimizing test volume in the process of complex products development while performing requirements of technical specifications (TS) for reliability.

In the development and creation of complex products in the test program, in every kind of test $j=\overline{1, p}$, a certain amount of goods is set $n_{j}\left(n_{i}=0,1,2, \ldots\right)$, which should be tested in every test for confirming TS requirements.

If there are indicators of reliability in every parameter, for example, as the lower limit of failure-free operation probability $\left(\frac{P^{\mathrm{Tp}}}{1} ;\right)$, at a certain confidence level of $\gamma^{\mathrm{Tp}}$ the

\footnotetext{
*Corresponding author: ycarev@,donstu.ru
} 
process of creating such a product can be presented in the form of a continuous chain growth for every parameter, in the absence of failures

$$
\underline{Ð}_{y}\left(Y \in\left\{Y^{\ddot{A}}\right\} \geq \underline{Ð}_{y}^{\text {ò }}\right.
$$

where $Y=\left[y_{1}, \ldots, y_{d}\right], \forall y_{i} \in\left\{y_{i}^{\text {д }}\right\}, i=\overline{1, d}$, vector of output parameters (power, traction, industrial and other characteristics which determine how to use a product as an object), satisfying suitability criterion where $\left\{y_{i}^{\text {म }}\right\}$ is a range of permissible values of parameters given by a TS in an unilateral upper (lower) limit or double; $\underline{D}_{y}, \underline{Ð}_{y}^{\mathrm{o} \delta}$ is an uptime condition and quality criteria defined in the output settings in the product $\mathrm{Y}$ of TS as the lower limit of failure-free probability operation with a certain confidence level.

In case of device failure or its parts in any period of testing, the test will be ended, a cause will be searched, a reason will be determined, a completion of a product or its part will be made, general entirety will be changed and if the failure is structural in nature, all the tests seem to be necessary to start over, to check the efficiency improvements and fulfill the requirements of the TS for the product creation. This is typical of the product which is regarded as a system consisted of individual elements (Fig. 1).

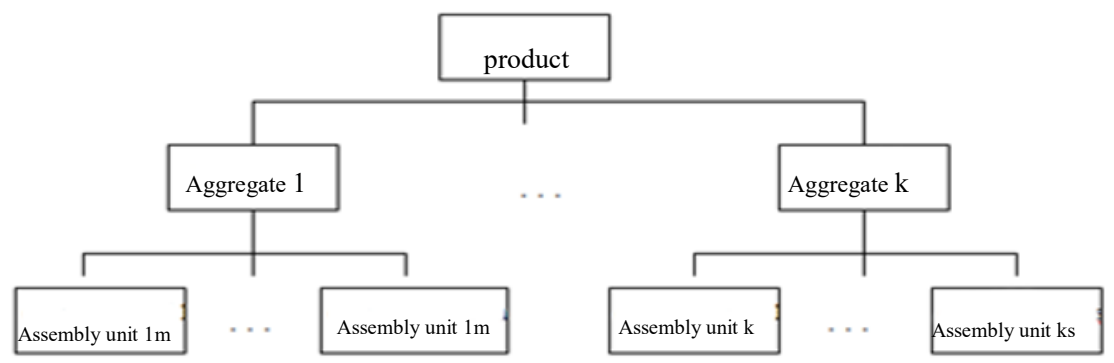

Fig. 1. The structural diagram of the product as a system consisting of individual elements

If we consider the product in the process of its creation in the form of a continuous chain growth for every parameter, in case of structural failure and successful improvements in any kind of tests by a particular parameter, it becomes possible to use a priori information by taking into account previous positive tests, thereby reducing the total volume of the test product compared to the representation in the form of a system consisting of individual elements.

For example, for a product structure (Fig. 2): $d=3$ - the number of output parameters and $\mathrm{p}=5$ is a number of test types, the testing process can be represented in parametric form. Here $Z=\left[z_{1}, z_{2}, z_{3}, z_{4}, z_{5}\right], j=\overline{1,5}$ is some test program consisting of test types defined TS; $Y=\left[y_{1}, y_{2}, y_{3}\right], i=\overline{1,3}$ is a vector output of controllable parameters; $X=\left[X_{1}^{c \sigma}, X_{2}^{c \sigma}, X_{3}^{c \sigma}\right]$ is a vector of structural parameters. 


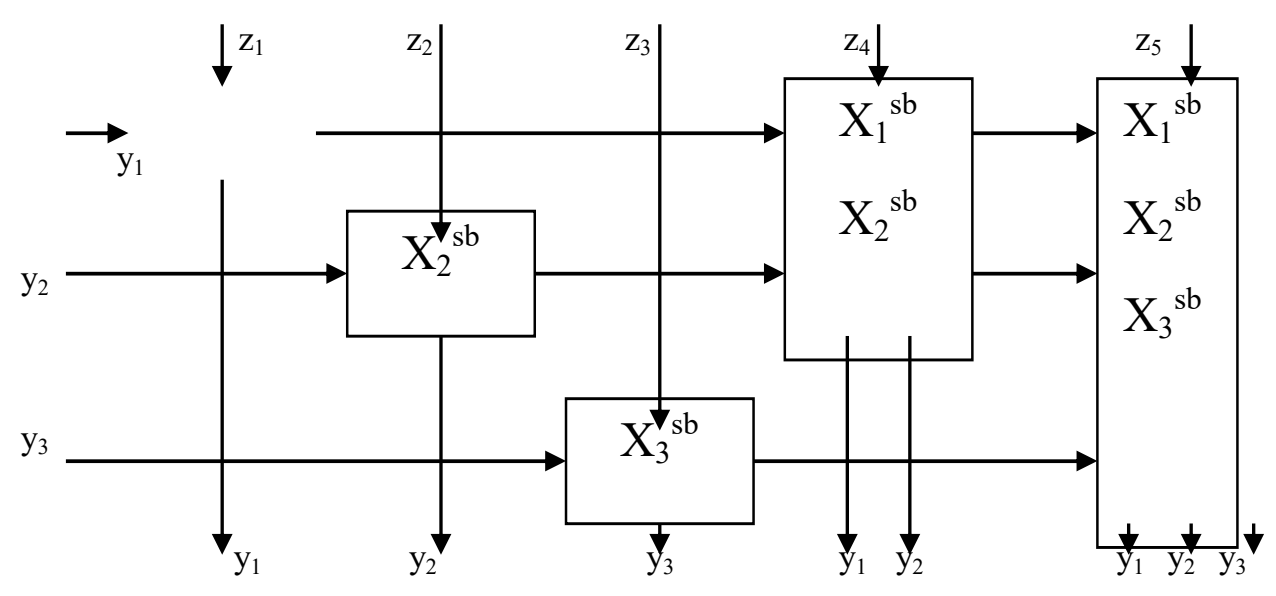

Fig. 2. The process of test product presented in the form of a parametric functional model of a product can be generally represented by [1]:

$$
Y=f(X, Z, N)
$$

where $Z=\left[z_{1}, \ldots, z_{p}\right], j=\overline{1, p}$.

test program; $X$ (geometry, weight, physics, chemistry and other characteristics which determine how the product manufacturing facility) satisfying suitability criterion, where $\left\{x_{r}^{\not}\right\}$ is the range of permissible values of $\mathrm{xr}$, represented in design documents (DD) as a unilateral upper (lower) or double limit;

$$
N=\left[n_{1}, \ldots, n_{p}\right], j=\overline{1, p} \text { is vector of test product object replicates (product or its }
$$
components) in every test form.

The solution of the problem $(1,2)$ is possible by introducing the objective function cost or time to create the product, as the optimal control problems and scheduling tests, for example,

$$
C=\min , \underline{Ð} \geq \underline{Ð}^{\text {̀̀ }}, \grave{O} \leq \grave{O}^{\text {̀̀ }},
$$

where $\mathrm{C}$ is testing costs associated with the development and creation of products;

$$
\underline{\Xi}^{\mathrm{\partial ळ}}, \dot{O}^{\mathrm{o} \delta} \text { are required values of reliability and time to design and develop products. }
$$

Time and cost of product development and creation depends on the number of products samples manufactured and supplied to the test, as well as the costs, such as those, associated with the test base $C^{b}$. In this case, the time limit is often removed, and then optimization problem (3) has the following form:

To find $\mathrm{n}^{*}$, basis of the conditions

$$
\begin{gathered}
\min : C=C(X, Z, N)+C^{\sigma}, \\
x^{*} \in X \\
z^{*} \in Z
\end{gathered}
$$


under restrictions:

$$
n^{*} \in N,
$$

$$
\underline{Ð}_{Y}\left(Y \in\left\{Y^{\tilde{A}}\right\}\right) \geq \underline{Ð}_{Y}^{\mathrm{o} \delta}
$$

where $\mathrm{n}^{*}$ is optimization parameters on the test volume; $\mathrm{x}^{*}, \mathrm{z}^{*}$ - conditions for conformance with the design parameters and types of tests related to the development and creation of products.

If we use binomial scheme while evaluating the results of tests, when we consider the sequence of nj of independent tests conducted under the same conditions, in every of which there are two possible outcomes: success or failure, for a small number of trials the best estimation is the use of confidence intervals at a confidence level that can be determined from the equations Klopper- Pearson [4-6]:

$$
\begin{aligned}
& 1-\gamma_{i j}=\sum_{m i j=0}^{k i j} C_{n i j}^{m i j} \underline{P}_{i j}^{(n i j-m i j)}\left(1-\underline{P}_{i j}\right)^{m i j}, \\
& 1-\gamma_{i j}=\sum_{m i j-k i j}^{n i j} C_{n i j}^{m i j} \bar{P}_{i j}^{(n i j-m i j)}\left(1-\bar{P}_{i j}\right)^{m i j},
\end{aligned}
$$

describing thereby binomial distribution $n_{i j}-m_{i j}$, where $C_{n i j}^{m i j}=\frac{n_{i j} !}{m_{i j} !\left(n_{i j}-m_{i j}\right) !} ; \quad \underline{P}_{i j}, \bar{P}_{i j}$ roots of Klopper-Pearson equations; $\underline{P}_{i j}$ is the lower limit of the i parameter product in $\mathrm{j}$ testing form, the plan acceptance inspection $\underline{P}_{i j} \geq \underline{P}_{i j}^{\mathrm{Tp}} ; \bar{P}_{i j}$ is the upper limit of PFW products; $m_{i j}=0,1,2, \ldots$ number of structural failures when $y_{i j} \notin\left\{y_{i}^{\not}\right\}$.

Let us consider the problem (Figure 2.) related to the calculation of the test volume for the case $\mathrm{m}_{\mathrm{ij}}=0$, hen all the parameters put under conditions: $\underline{P}_{i j}^{\mathrm{Tp}}=0,9 ; \gamma_{i j}^{\mathrm{Tp}}=0,9$; $i=\overline{1,3}$, the importance of every test type is $\mathrm{P}_{1}{ }^{\mathrm{B}}-\mathrm{P}_{3}{ }^{\mathrm{B}}=0,33 ; \mathrm{P}_{4}{ }^{\mathrm{B}}=0,67 ; \mathrm{P}_{5}{ }^{\mathrm{B}}=1 ; P_{j}^{\mathrm{a}}$ $=0,9 ; j=\overline{1,5}$, costs associated with the tests on every type of $\mathrm{C}_{1}-\mathrm{C}_{3}=1 ; \mathrm{C}_{4}=2 ; \mathrm{C}_{5}=5$; $\mathrm{C}_{6}$ is not taken into account; $\mathrm{x}^{*} \in \mathrm{X}$ и $\mathrm{z}^{*} \in \mathrm{Z}$ are defined. Mathematically, the problem (4 7) can be represented by $[1,2]$ :

$$
\begin{aligned}
& \text { min: } \mathrm{C}=\mathrm{C}_{1} \mathrm{~N}_{1}+\mathrm{C}_{2} \mathrm{~N}_{2}+\mathrm{C}_{3} \mathrm{~N}_{3}+\mathrm{C}_{4} \mathrm{~N}_{4}+\mathrm{C}_{5} \mathrm{~N}_{5} \\
& n^{*} \in N
\end{aligned}
$$

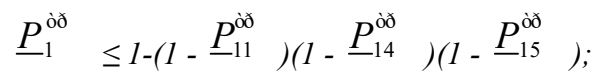

$$
\begin{aligned}
& \underline{P}_{2}^{\text {ö }} \leq 1-\left(1-\underline{P}_{22}^{\text {o }}\right)\left(1-\underline{P}_{24}^{\text {ò }}\right)\left(1-\underline{P}_{25}^{\text {ó }}\right) \text {; } \\
& \underline{P}_{3}^{\text {o̊ }} \leq 1-\left(1-\underline{P}_{33}^{\text {o }}\right)\left(1-\underline{P}_{35}^{\text {o̊ }}\right), \\
& \underline{P}_{11}^{\text {oळ }} \leq \underline{P}_{11}^{\prime}=P_{1}{ }^{{ }^{6}} \underline{P}_{11}=P_{1}{ }^{6} f_{2}\left(n_{11}, m_{11}, \gamma^{m p}\right) \text {; } \\
& \underline{P}_{14}^{\text {o }} \leq \underline{P}_{14}^{\prime}=P_{4}{ }^{6} \underline{P}_{14}=P_{4}{ }^{6} f_{2}\left(n_{14}, m_{14}, \gamma^{m p}\right) \text {; } \\
& \underline{P}_{15}^{\text {o̊ }} \leq \underline{P}_{15}^{\prime}=P_{5}{ }^{6} \underline{P}_{15}=P_{5}{ }^{6} f_{2}\left(n_{15}, m_{15}, \gamma^{m p}\right) \text {; } \\
& \underline{P}_{22}^{\text {ò }} \leq \underline{P}_{22}^{\prime}=P_{2}{ }^{6} \underline{P}_{22}=P_{2}{ }^{6} f_{2}\left(n_{22}, m_{22}, \gamma^{m p}\right) \text {; } \\
& \underline{P}_{24}^{\text {o d }} \leq \underline{P}_{24}^{\prime}=P_{4}{ }^{{ }^{\circ}} \underline{P}_{24} \quad=P_{4}{ }^{8} f_{2}\left(n_{24}, m_{24}, \gamma^{m p}\right) ; \\
& \underline{P}_{25}^{\text {o }} \leq \underline{P}_{25}^{\prime}=P_{5}{ }^{6} \underline{P}_{25}=P_{5}{ }^{6} f_{2}\left(n_{25}, m_{25}, \gamma^{m p}\right) \text {; }
\end{aligned}
$$




$$
\begin{aligned}
& \underline{P}_{33}^{\text {о ठ }} \leq \underline{P}_{33}^{\prime}=P_{3}{ }^{{ }} \underline{P}_{33}=P_{3}{ }^{6} f_{2}\left(n_{33}, m_{33}, \gamma^{m p}\right) ; \\
& \underline{P}_{35}^{\text {oठ }} \leq \underline{P}_{35}^{\prime}=P_{5}{ }^{\circ} \underline{P}_{35}=P_{5}{ }^{6} f_{2}\left(n_{35}, m_{35}, \gamma^{m p}\right) \text {, }
\end{aligned}
$$

$\mathrm{N}_{1} *=n_{11}, \mathrm{~N}_{2} *=n_{22}, \mathrm{~N}_{3}^{*}=n_{33}, \quad N_{4}^{*}=\max \left(n_{14} ; n_{24}\right), \quad N_{5}^{*}=\max \left(n_{15} ; n_{25} ; n_{35}\right)$, or after substituting the numerical values in $(8,9)$ :

min: $\mathrm{C}=\mathrm{N}_{1}+\mathrm{N}_{2}+\mathrm{N}_{3}+2 \mathrm{~N}_{4}+5 \mathrm{~N}_{5}$

$$
\mathrm{n}^{*} \in \mathrm{N}
$$

$$
\begin{aligned}
& 0,9 \leq 1-\left(1-\underline{P}_{11}^{\text {oð }}\right)\left(1-\underline{P}_{14}^{\text {ò }}\right)\left(1-\underline{P}_{15}^{\text {o̊ }}\right) ;
\end{aligned}
$$

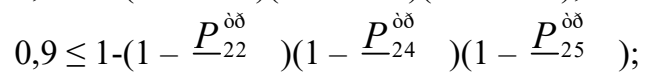

$$
\begin{aligned}
& 0,9 \leq 1-\left(1-\underline{P}_{33}^{\text {o̊ }}\right)\left(1-\underline{P}_{35}^{\text {o̊ }}\right) \text {; } \\
& \underline{P}_{11}^{\text {o̊ }} \leq \underline{P}_{11}^{\prime}=0,33 \underline{P}_{11}=0,33 \text { f2 }\left(\mathrm{n}_{11}, 0,0,9\right) ; \\
& \underline{P}_{14}^{\text {o̊ }} \leq \underline{P}_{14}^{\prime}=0,67 \underline{P}_{14}=0,67 \mathrm{f} 2\left(\mathrm{n}_{14}, 0,0,9\right) \text {; } \\
& \underline{P}_{15}^{\text {oð }} \leq \underline{P}_{15}^{\prime}=\underline{P}_{15}=\mathrm{f} 2\left(\mathrm{n}_{15}, 0,0,9\right) \text {; } \\
& \underline{P}_{22}^{\text {ò }} \leq \underline{P}_{22}^{\prime}=0,33 \underline{P}_{22}=0,33 \mathrm{f} 2\left(\mathrm{n}_{22}, 0,0,9\right) \text {; } \\
& \underline{P}_{24}^{\text {о }} \leq \underline{P}_{24}^{\prime}=0,67 \underline{P}_{24}=0,67 \mathrm{f} 2\left(\mathrm{n}_{24}, 0,0,9\right) \text {; } \\
& \underline{P}_{25}^{\text {o }} \leq \underline{P}_{25}^{\prime}=\underline{P}_{25}=\mathrm{f} 2\left(\mathrm{n}_{25}, 0,0,9\right) \text {; } \\
& \underline{P}_{33}^{\text {о̆ }} \leq \underline{P}_{33}^{\prime}=0,33 \underline{P}_{33}=0,33 \mathrm{f} 2\left(\mathrm{n}_{33}, 0,0,9\right) \text {; } \\
& \underline{P}_{35}^{\text {oð }} \leq \underline{P}_{35}^{\prime}=\underline{P}_{35}=\mathrm{f} 2\left(\mathrm{n}_{35}, 0,0,9\right),
\end{aligned}
$$

$\mathrm{N}_{1} *=\mathrm{n}_{11}, \mathrm{~N}_{2} *=\mathrm{n}_{22}, \mathrm{~N}_{3} *=\mathrm{n}_{33}, \mathrm{~N}_{4} *=\max \left(\mathrm{n}_{14} ; \mathrm{n}_{24}\right), \mathrm{N}_{5} *=\max \left(\mathrm{n}_{15} ; \mathrm{n}_{25} ; \mathrm{n}_{35}\right)$.

This is nonlinear programming problem, where: (8) - the objective function, (9) nonlinear constraints which can be solved by using a program directed enumeration method (e.g., the first parameter, Fig 3.) [3, 4]. For the formation of the test program product for the case when all $\mathrm{m}_{\mathrm{ij}}=0$ :

$$
\mathrm{N}_{1} *=2, \mathrm{~N}_{2} *=2, \mathrm{~N}_{3}^{*}=6, \mathrm{~N}_{4} *=2, \mathrm{~N}_{5} *=17, \mathrm{C}=91
$$

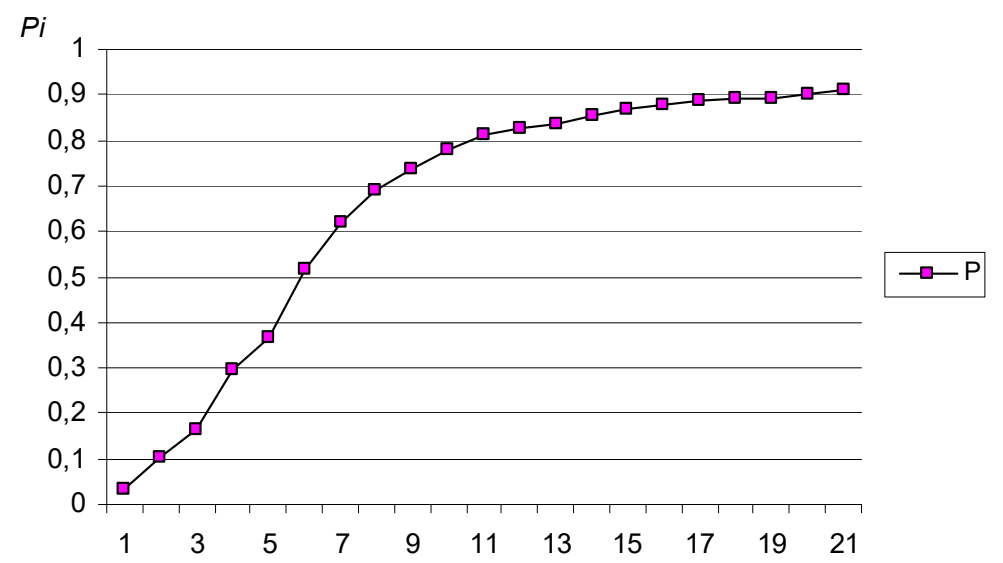

Fig. 3. The growth of the first parameter product reliability $\left(\mathrm{N}_{1} *=2, \mathrm{~N}_{4} *=2, \mathrm{~N}_{5} *=17, m_{i j}=0\right)$ 
Let us assume that in the fifth stage, which is typical of products in the tenth testing in the first parameter, a structural failure occurred $\left(\mathrm{m}_{15}=1\right)$. How must the test program changed, taking into account the priori information, if the cause is established and completion is held? Otherwise, after completion, all 17 tests must be carried out again.

In this case, the mathematical problem $(8,9)$ may take the form [1]:

$\min : C=N_{1}+N_{2}+N_{3}+2 N_{4}+5 N_{5}$

$$
\begin{aligned}
& n^{*} \in N \\
& 0,9 \leq 1-\left(1-\underline{P}_{11}^{\mathrm{o} \gamma}\right)\left(1-\underline{P}_{14}^{\mathrm{o} \gamma}\right)\left(1-\underline{P}_{15}^{\mathrm{o} \delta}\right) \text {; } \\
& 0,9 \leq 1-\left(1-\underline{P}_{22}^{\text {o }}\right)\left(1-\underline{P}_{24}^{\text {ò }}\right)\left(1-\underline{P}_{25}^{\text {oð }}\right) \text {; } \\
& 0,9 \leq 1-\left(1-\underline{P}_{33}^{\text {oð }}\right)\left(1-\underline{P}_{35}^{\text {oð }}\right) \text {, } \\
& \underline{P}_{11}^{\text {oð }} \leq \underline{P}_{11}^{\prime}=0,33 \underline{P}_{11}=0,33 f_{2}\left(n_{11}, 0,0,9\right) \text {; } \\
& \underline{P}_{14}^{\text {o̊ }} \leq \underline{P}_{14}^{\prime}=0,67 \underline{P}_{14}=0,67 f_{2}\left(n_{14}, 0,0,9\right) \text {; } \\
& \underline{P}_{15}^{\mathrm{o} ð} \leq \underline{P}_{15}^{\prime}=\underline{P}_{15}^{\mathrm{i}}+\underline{P}_{15} \quad\left(\underline{P}_{15}^{\mathrm{a}}-\underline{P}_{15}^{\mathrm{i}}\right) ; \\
& \underline{P}_{15}=f_{2}\left(n_{15}, 0,0,9\right) \text {; } \\
& \underline{P}_{15}^{\mathrm{i}}=f_{2}(10,1,0,9)=0,663 ; \forall^{P_{i j}^{\prime}} \in\left[\underline{P}_{15}^{\mathrm{i}}, \underline{P}_{15}^{\hat{\mathrm{a}}} \quad\right] \text {; } \\
& \underline{P}_{15}^{\hat{\mathrm{a}}}=0,9 \text {; } \\
& \underline{P}_{22}^{\text {o d }} \leq \underline{P}_{22}^{\prime}=0,33 \underline{P}_{22}=0,33 f_{2}\left(n_{22}, 0,0,9\right) \text {; } \\
& \underline{P}_{24}^{\text {оð }} \leq \underline{P}_{24}^{\prime}=0,67 \underline{P}_{24}=0,67 f_{2}\left(n_{24}, 0,0,9\right) \text {; } \\
& \underline{P}_{25}^{\text {о ठ }} \leq \underline{P}_{25}^{\prime}=\underline{P}_{25}=f_{2}\left(n_{25}, 0,0,9\right) \text {; } \\
& \underline{P}_{33}^{\text {о ठ }} \leq \underline{P}_{33}^{\prime}=0,33 \underline{P}_{33}=0,33 f_{2}\left(n_{33}, 0,0,9\right) \text {; } \\
& \underline{P}_{35}^{\text {od }} \leq \underline{P}_{35}^{\prime}=\underline{P}_{35}=\mathrm{f} 2\left(\mathrm{n}_{35}, 0,0,9\right),
\end{aligned}
$$

$\mathrm{N}_{1} *=\mathrm{n}_{11}, \mathrm{~N}_{2} *=\mathrm{n}_{22}, \mathrm{~N}_{3}^{*}=\mathrm{n}_{33}, \mathrm{~N}_{4} *=\max \left(\mathrm{n}_{14} ; \mathrm{n}_{24}\right), \quad \mathrm{N}_{5}^{*}=\max \left(\mathrm{n}_{15} ; \mathrm{n}_{25} ; \mathrm{n}_{35}\right)$.

Solving the problem of mathematical programming relatively $\mathrm{N}$, when $\mathrm{m}_{15}=1[5-8]$ :

$\mathrm{N}_{1} *=2+2, \mathrm{~N}_{2} *=2, \mathrm{~N}_{3} *=6, \mathrm{~N}_{4} *=2+1, \mathrm{~N}_{5} *=10+8, \mathrm{C}=100$.

Graphically it can be represented, for example, for the first parameter, fig. four (Fig 4.).

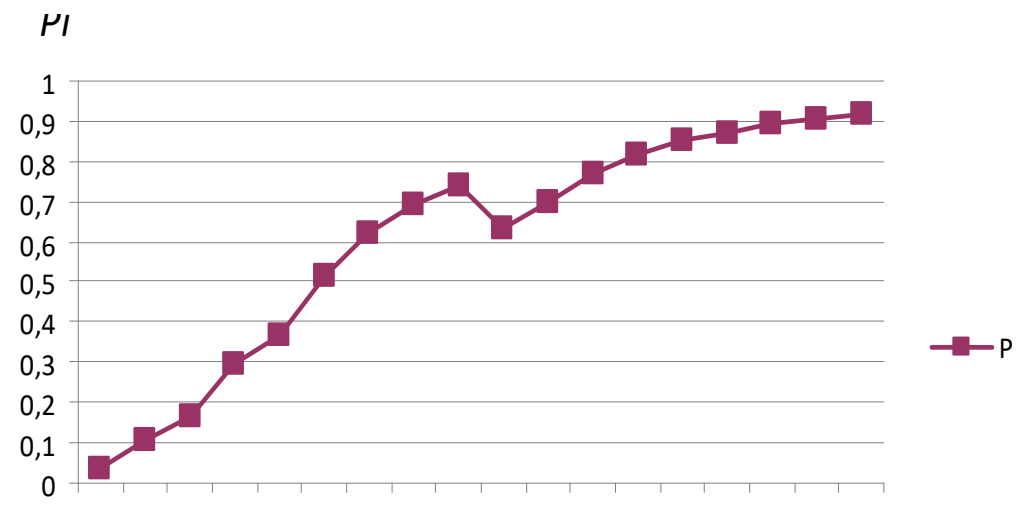

$\begin{array}{llllllllllllllllll}1 & 2 & 3 & 4 & 5 & 6 & 7 & 8 & 9 & 10 & 11 & 12 & 13 & 14 & 15 & 16 & 17 & 18\end{array}$ 
Fig. 4. The growth of product reliability taking into account the priori information by the first parameter $\left(\mathrm{N}_{1} *=4, \mathrm{~N}_{4} *=3, \mathrm{~N}_{5} *=18, \mathrm{~m}_{15}=1\right)$

In general, the process of creating (mining) complex technical products of a single use in parametric form (the parameters) can be represented, fig. five (Fig 5.) [9-12].

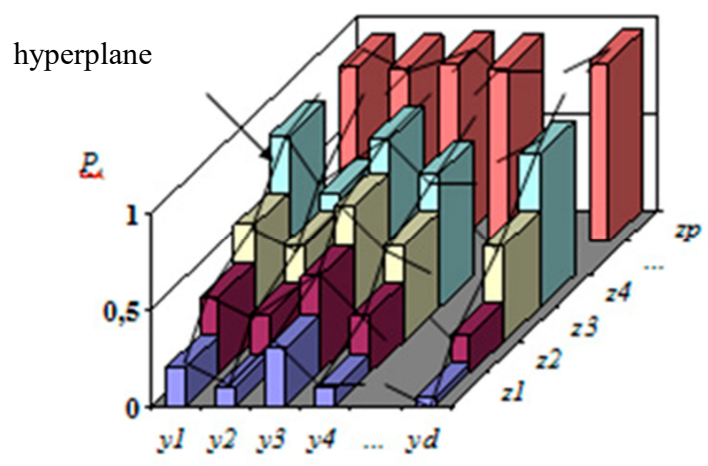

Fig. 5. Fragment of reliability hyperplane growth parameters experienced during the mining of the test species

\section{Conclusion}

Thus, accounting a priori information after processing is that for meeting all the requirements of TS, one should perform 2 extra successful tests, in the fourth-one and 8 in the last form testing [13-15].

Similar calculations can be carried out for all situations, however, if the structural failures are continuous, it is obvious that this project should be ended, due to a substantial increase in the cost or time which is spend for its creation. However, everything depends on the choice of the initial phase values $\underline{P}_{i j}^{\mathrm{a}}$ and $\mathrm{P} 1 \mathrm{~B}, i=\overline{1, d}, j=\overline{1, p}$

\section{References}

1. Y.A. Tsarev, A.A. Kharkovsky, Tractors and agricultural machinery 1(2005).

2. A.I. Demin, Relata Refero: The paradigm of duality: the space - time, informationenergy (2007).

3. Y.A. Tsarev, Planning and management capacity testing of complex technical products in a comprehensive program of experimental development. Rostov-on-Don, DSTU (2009).

4. Y.A. Tsarev, A.R. Aidinyan, Planning and management capacity testing of complex technical products in a comprehensive program of experimental development. Certificate of computer programs of state registration 2009615291 Russian Federation.

5. V.I. Chernoivanov, A.A. Ezhevsky, N.V. Krasnochekov, Machinery and equipment for the village 6 (2009).

6. Y.A. Tsarev, A.R. Lebedev, D.G. Dzhigarkhov, Tractors and agricultural machinery 4 (2009).

7. A.S. Ksenofontov, Study book of KBSU: The reliability of technical systems (2010).

8. Y.A. Tsarev, Vestnik of Don Agrarian Science (Zernograd) 4(16) (2011). 
9. S.M. Krasnostup, A.G. Dalaliyants, Y.A. Tsarev, Testing of agricultural machines and implements for field crop cultivation. Rostov-on-Don: study book of DSTU (2012).

10. Y.A. Smirnov, Y.A. Tsarev, Automatization basic of AGM. Rostov-on-Don: a study book for students of Higher Education (2013).

11. Y.I. Eremenko, S.N. Uksusov, Y.M. Fetisov, Intelligent decision-making system and management Publ. house: Thin high-end technologies: Mathematics (2016).

12. S.V. Bochkarev, A.I. Tsaplin and others, Diagnostics and reliability of automated technological systems. Publ.house: Thin high-end technologies (2016).

13. S.N. Uksusov, Y.M. Fetisov, Mathematics. Publ.house: Thin high-end technologies (2016).

14. A.I. Barbotko, A.O. Gladishkin, Basics of mathematical modeling theory. Publ.house: Thin high-end technologies (2016).

15. E.A. Boitsova, Workshop on Mathematics. Publ.house: Thin high-end technologies (2016). 